Forthcoming as: Kalafatis, S.P., Blankson, C., Boatswain, M.L. and Tsogas, M.H. (2020), "Preference for action: regulatory mode in B2B positioning decision-making", Journal of Business \& Industrial Marketing, Vol. aheadof-print No. ahead-of-print. https://doi.org/10.1108/JBIM-04-2019-0145 


\section{PREFERENCE FOR ACTION: REGULATORY MODE IN B2B POSITIONING DECISION MAKING}

\begin{tabular}{|r|l|}
\hline Journal: & Journal of Business and Industrial Marketing \\
\hline Manuscript ID & JBIM-04-2019-0145.R4 \\
\hline Manuscript Type: & Original Article \\
\hline Keywords: & Positioning strategies, Regulatory mode, Experiments \\
\hline \multicolumn{2}{|l}{} \\
\end{tabular}

SCHOLARONE $^{\mathrm{m}}$
Manuscripts 


\title{
Preference for Action: Regulatory Mode in B2B Positioning Decision Making
}

\begin{abstract}
Purpose - Grounded in regulatory mode theory (RMT), this study investigates the impact of managers' orientations for action (locomotion and assessment) in B2B positioning decision making.
\end{abstract}

Design/methodology/approach - Data are collected using a scenario-based experimental design. Study 1 examines whether interest and involvement in recommending a positioning strategy depends on a manager's regulatory mode orientation. The impact of such orientations on the likelihood of changing a recommended positioning strategy is the focus of Study 2 . The moderating effects of task motivation (expected rewards resulting from a recommendation), market feedback, and the line manager's leadership style are examined. Findings - Both assessment and locomotion are significant determinants of involvement in recommending a positioning strategy. The introduction of motivation as a moderator helps explain differences in level of interest in positioning decision making. Locomotion, but not assessment, affects the likelihood of changing a recommended positioning strategy.

Assessment amplifies the impact of locomotion, while none of the interaction effects between regulatory mode orientation and contextual factors is a significant determinant of changing a positioning strategy.

Originality/value - This is the first application of regulatory mode theory on positioning decision making. Results from two experiments provide novel insights into the predictive relevance of managers' preferences in terms of involvement with the decision-making process and the likelihood of altering positioning.

Keywords: Positioning strategies, Positioning decision making, Regulatory mode, Experiments

Paper type: Research paper 


\section{Introduction}

Marketing literature converges on the view that competitive positioning is at the core of marketing theory and practice (Hooley et al., 2001; Urde \& Koch, 2014). Although a number of scholars - including Penttinen and Palmer (2007), Rodríguez-Pinto et al. (2008), Zahay and Griffin (2010), and Iyer et al. (2019) — do not offer formal definitions, the views of Ries and Trout (1986) and Kotler and Armstrong (2014) are either explicit or implicit in B2B positioning research. Jalkala and Keränen (2014, p. 254), McColl et al. (2019), and Panda et al. (2019) all consider positioning to be "the act of designing the company's offering and image to occupy a distinctive place in the mind of the target market." Kalafatis et al. (2000, p. 417) elaborate on temporal aspects, stating that "positioning is the deliberate, proactive, iterative process of defining, modifying and monitoring consumer perceptions of a marketable object" (see also Diwan \& Bodla, 2011). Iyer et al. (2019) identify competitive differentiation as an essential aspect of positioning. At the same time, Zahay and Griffin (2010) emphasize the role of company competencies and resources in developing a superior competitive position, and Makkonen et al. (2019) include value creation as a positioning activity. In this study, we focus on managers' involvement and interest in recommending a positioning strategy that a company should pursue compared to its competitors; we also examine the drivers that influence the likelihood of altering these recommendations.

Although we recognize that positioning involves a dynamic set of deliberations and activities that are institutionally defined and constrained (Koch \& Gyrd-Jones, 2019), we adopt the structural perspective of an employee or manager rather than an organization (see Sok et al., 2016, pp. $145-146)$.

Research within the B2B domain is limited, which is a point expressed by Iyer et al. (2019, p. 17): "there is [a] lack of understanding about positioning and its relationship with its antecedents and outcomes in B2B context[s]." This observation is echoed by Panda et al. 
(2019, p. 32), who state that "little is known in the academic literature about positioning strategies used in B2B context[s]." Nevertheless, as the brief commentary below demonstrates, there is progress. Several studies focus on either developing B2B positioning typologies (Kalafatis et al., 2000; Panda et al., 2019) or identifying the dominant positioning strategies in different B2B market sectors (Diwan \& Bodla, 2011; Amonini et al., 2010; Jalkala \& Keränen, 2014). In terms of drivers of positioning decisions, Rodríguez-Pinto et al. (2008) find that market entry decisions affect positioning strategies, while Iyer et al. (2019) demonstrate the impact of market orientation on the adoption of positioning strategies. As for outcomes, Iyer et al. (2019) find a differential impact of the positioning strategies proposed by Henry Mintzberg on brand performance, whereas Panda et al. (2019) report a positive relationship between positioning strategies, franchise fees, and royalties. Penttinen and Palmer (2007) develop a framework for strategic repositioning decisions, while Koch and Gyrd-Jones (2019) introduce a dynamic process approach to positioning. Further, Makkonen et al. (2019) use exchange logic to develop a framework for positioning grounded on a relational perspective.

Although the foregoing discussion offers insights, extant literature focuses on the question of "what" (i.e., positioning typologies and strategies applied in different B2B contexts) or adopts a corporate perspective (e.g., drivers and consequences of positioning actions) and is silent regarding the cognitive mechanisms involved in positioning decisions. We consider the omission of examinations of managerial motivations in positioning decision making to be an important research gap that this study attempts to address. B2B marketing literature offers supports the adoption of motivation as the theoretical underpinning of our study. Lewin and Johnston (1996) present an early discussion, and subsequent studies provide empirical evidence that motivation is a significant driver of behavior in the B2B domain. For example, Bande et al. (2016) establish the impact of motivations on engendering proactivity 
and adaptability, while Korhonen-Sande and Sande (2016) employ intrinsic motivation to explain knowledge transfer. Additionally, Rajabi et al. (2018) find a significant relationship between entrepreneurial motivation and effort, and Nowlin et al. (2018) reveal the mediating effects of motivation on the functional relationship between affective orientation and salespeople's performance. Compared to the above studies, which adopt affective perspectives, this study locates motivation within self-regulation. We focus on motivational preference for action, and more specifically, strategic decisions related to a company's positioning strategy.

In the following widely quoted definition, Robbins (1998, p. 168) considers motivation to represent "willingness to exert high levels of efforts toward organizational goals, conditioned by the effort's ability to satisfy some individual need." It therefore follows that the motivations associated with managerial decision making are framed by both personal and organizational considerations. Recent advances in motivational theory grounded in selfregulation account for the implicit alignment of personal goals and organizational objectives. Kruglanski et al. (2000, p. 794) state that "self-regulation involves comparing and selecting among alternative desired end-states, comparing and selecting among alternative means to attain the selected desired end-state, and initiating and maintaining movement from some current state toward the desired end-state until the desired end-state is attained." The resulting sequence of individuals establishing goals, identifying actions designed to achieve these goals, and finally enacting the selected actions (Chen et al., 2018) mirrors positioning decision making.

Located within the domain of self-regulation, regulatory mode theory (RMT) "emphasizes the 'how' of goal pursuit" (Pierro et al., 2018, p. 245). We argue that the behavior orientation of RMT provides an appropriate analytical platform that helps us examine the role of managerial motivations in $\mathrm{B} 2 \mathrm{~B}$ positioning decision making. By 
categorizing motivation into two main orientations (see below debate on assessment and locomotion), RMT overcomes shortcomings in extant studies that either treat motivation as a single construct (e.g., Mayo \& Mallin, 2014; Bande et al., 2016) or consider it as an abstract notion (e.g., Mehta et al., 2000; Lin, 2017). To our best knowledge, this is the first study that examines the role of regulatory mode orientations within the context of positioning-related decisions across market and industry domains.

\section{Regulatory Mode Theory}

Before presenting the two main components of RMT (locomotion and assessment), we provide a brief background of the development of the theory; the interested reader is directed to Weiland (2007) and Pierro et al. (2018). RMT is located within the broad domain of selfregulation, which refers to "operations through which one can achieve their goals" (Weiland, 2007, p. ii), or "the procedure implemented by an individual striving to reach a goal" (Garcia et al., 2015, p. 1). The following from Higgins et al. (2003, p. 293) states that "the everyday conceptualization of self-regulation is that individuals decide what they want that they do not currently have, figure out what they need to do to get what they want, and then do it." Higgins et al.'s definition links self-regulation with motivation, decision making, and action (see also Köpetz et al., 2013, p. 8). Comparison or testing (evaluating the current state against a desired state) and change or action (attempting to reduce the discrepancy between current and desired states by any means available) are the two components of self-regulation. These two components are "interdependent parts that make up the whole of self-regulation" (Weiland, 2007, p. 24). Pierro et al. (2018, p. 251) present the following illustrative example: "the functioning of this psychological system can be compared to a thermostat, which has a sensor that detects whether a room is at the desired temperature. If it is already at that 
temperature, then no action occurs. If it is not, then a heating or cooling process turns on until the room has reached the desired temperature."

RMT focuses on the preference for action and conceptualizes comparison (or testing) as assessment and change (or action) as locomotion; furthermore, RMT proposes that these two components "are independent operating modes that have equal regulatory status in that either mode is capable of receiving primary emphasis at any given point during goal pursuit" (Weiland, 2007, p. 25). According to Kruglanski et al. (2000), locomotion "constitutes the aspect of self-regulation concerned with movement from state-to-state and with committing the psychological resources that will initiate and maintain goal-related movement in a straightforward and direct manner, without undue distraction or delays" (Kruglanski et al., 2000, p. 794). "Doing," "hurrying," “getting on with it," and “making things happen” characterize individuals with strong locomotion orientation, who are known as "locomotors" (Higgins et al., 2003). Locomotors demonstrate quick decision making and initiation of action, consider moving from one state to another as rewards, and desire to complete tasks quickly. In comparison, assessment "constitutes the comparative aspect of self-regulation concerned with critically evaluating entities or states, such as goals or means, in relation to alternatives in order to judge relative quality" (Kruglanski et al., 2000, p. 794). Individuals high in assessment orientation (known as "assessors") demonstrate a critical tendency that involves understanding, detailed interpretation, and evaluation of alternatives, and therefore their emphasis is on making the correct decision rather than moving forward. Higgins et al. (2003) attribute the following questions to assessors: "What are my options? Are there any possibilities worth considering? Which alternative is best?"

Locomotion or assessment tendencies influence an individual's behavior "either as chronic personality dispositions (orientations developed from caretaker-child interactions) or momentarily as situationally induced states" (Panno et al., 2015, p. 2). Kruglanski et al. 
(2010, p. 376) state that "situations may arouse the operation of one mode over the other. In this sense, assessment and locomotion represent both individual difference and situational variables.” Reviewing empirical evidence, Kruglanski et al. (2013) conclude that locomotion and assessment "constitute largely autonomous dimensions on which individuals may vary, both stably over time and from moment to moment" and that the two orientations “demonstrate consistent complementarity effects" (p. 82). Therefore, an individual can be high on one orientation and low on the other or relatively high/low on both (Higgins et al., 2003).

Although the recent review by Pierro et al. (2018) evidences a wide range of applications of RMT, studies in business and management are limited. Nevertheless, we identify two fields of research, entrepreneurship, and salesforce performance which demonstrate the relevance of RMT to this study. Regarding the former, Davis et al. (1991) developed a logic that links entrepreneurial behavior with marketing, and Carvera et al. (2001) provide evidence of a significant relationship between entrepreneurship, market orientation, and the use of marketing information (both central in positioning-related decisions). Syed and Mueller (2014) find that locomotion has a positive impact on entrepreneurial perseverance (or "grit") while assessment has a negative impact. Amato et al. (2017) demonstrate differential effects of regulatory mode components on entrepreneurs' behaviors and perceptions of success, and research by Kraus et al. (2019) shows the opposing impact of assessment and locomotion on an entrepreneurial orientation and related exploitation and exploration activities. As for the latter, sales force performance is central in B2B marketing, and Jasmand et al. (2012), Sok et al. (2016), and Vieira et al. (2019) report a positive relationship between locomotion orientation and ambidexterity and the positive interaction effects of locomotion and assessment orientations on ambidextrous behavior. 


\section{Involvement and Interest: Regulatory Mode and Task Motivation}

Positioning decision making takes place in an environment characterized by time pressures, competing demands, and multitasking (see Koch \& Gyrd-Jones, 2019). Consequently, time management, speed of decision making, procrastination, and multitasking are germane managerial considerations. Individuals high in locomotion move forward rather than stand still, show a preference for beginning a task, expend effort on moving quickly to another task, and gain enjoyment by being in motion. Assessment orientation, by contrast, engenders comparison and reflects a preference for critical analysis. Therefore, preference for speedy completion of a task against thorough evaluation and comparison frame the respective decision-making preferences. Consistent with expectations, Mauro et al. (2009, p. 681) find that "groups containing only locomotors were faster in completing tasks compared to groups containing only assessors" and Pierro et al. (2006a) report a positive relationship between locomotion and time commitment. Pierro et al. (2011, p. 1318) state that "locomotors are unlikely to delay the initiation of tasks" and "individuals high on the assessment tendency... lead them to devote excessive time to their tasks." Their study shows a positive (negative) relationship between assessment (locomotion) and procrastination, and Zhang et al. (2017) corroborate these results. Multitasking is another manifestation of managerial time management and implies that less time is devoted to each specific task. Amato et al. (2019, p. 1107) suggest that "multitasking/polychronic behavior (i.e., performing multiple tasks simultaneously) are all time-related behaviors that locomotors use as means to reach their 'keep moving' goal, in order that they may quickly reach new states.' Research by Pierro et al. (2013) supports the above by showing a positive relationship between locomotion and multitasking. Based on the above debate, we hypothesize that:

$\mathrm{H}_{1}$ : There is a positive (negative) association between assessment (locomotion) orientation and involvement (time spent) in the process of recommending a positioning strategy. 
Self-determination theory differentiates between intrinsic and extrinsic types of motivations (Deci \& Ryan, 1985). Despite limited research, the B2B marketing literature provides some insights into the role of these types of motivation. Mehta et al. (2000) report differential importance of intrinsic and extrinsic rewards at different stages of managerial careers, while Pullins et al. (2000) argue that in buyer-seller relationships, intrinsic motivation increases the likelihood of cooperative offers. In the salesforce domain, Bande et al. (2016) indicate a positive relationship between intrinsic motivation and behavior, and Mallin and Ragland (2017) find that, of the two types, only intrinsic motivation affects performance.

Intrinsic and extrinsic motivations, in the form of related rewards, are relevant in RMT. Using flow theory, Higgins et al. (2003, p. 310) posit that "higher locomotion should be associated more with intrinsic than extrinsic engagement, whereas if anything, the reverse should be true for higher assessment." Locomotors' desire for movement implies that value is derived from engagement with a task and represents an autonomous or intrinsic motivation. Assessors' focus on analysis and comparison results in sensitivity to feedback (Kruglanski et al., 2010). Consequently, task engagement is a non-autonomous (extrinsic motivation). Studies by Kruglanski et al. (2000), Pierro et al. (2006b), Pierro et al. (2009), and Bélanger et al. (2015) corroborate the hypothesized relationships between the two orientations of regulatory mode and type of motivation. Therefore, the expectation is that, when faced with a positioning decision, assessors will invest more effort in the process when the incentive resulting from the decision is extrinsic. On the other hand, an intrinsic reward will encourage speed of action for individuals high in locomotion. Accordingly, we hypothesize that:

$\mathrm{H}_{2}$ : The positive (negative) association between assessment (locomotion) orientation and involvement (time spent) with the process of recommending a positioning strategy is greater when motivation is extrinsic (intrinsic). 
Interest in a task is a facet of flow and is contingent on the incentives associated with completing a task (Deci et al., 2001). Consistently, Pierro et al. (2006b) and Giacomantonio et al. (2013) report significant interactions between motivation and regulatory mode orientations on involvement and interest (former) and wellbeing (latter). Using logic similar to $\mathrm{H}_{2}$ we hypothesize that:

$\mathrm{H}_{3}$ : The positive association between assessment (locomotion) orientation and interest in the process of recommending a positioning strategy is greater when motivation is extrinsic (intrinsic).

\section{Study 1 - Method}

Design - To test the research hypotheses, we employed a scenario-based experimental design. A panel of experts assisted in the development of the scenarios. The building and allied sectors served as the industrial contexts, and to avoid potential confusion resulting from scenario complexity, a focal point and two competitors were included. Information from the webpages of companies operating in the selected sector and advice from the expert panel informed the profiles of the three companies (see Appendix A). Consistent with the definition of positioning in the introduction, the information and descriptions of the three companies align with core notions regarding positioning: namely, that it is a competence-derived, distinctive place in the mind of the target market and that the essential aspect of positioning is the way in which it differentiates a company from its competitors. Placing a statement about the positioning strategy of the two competitors at the end of the descriptions is intended to emphasize the focal interest of this study.

Procedure, data collection, and sampling - Data collection was carried out through a webbased survey by a specialist list broker. The population comprised a cross-section of 
individuals whose professional position was top-level or senior management/executive, middle-level manager, or first-level manager working in US-based companies that operate in B2B domains. The survey starts with questions about mood and regulatory mode. Mood is included in order "to check on whether the experimental framing manipulation itself or the tasks themselves create emotional effects" (Crowe \& Higgins, 1997; p. 121). The respondents were then randomly allocated to one of two experimental conditions. Extrinsic reward is described this way: “As a rising star in the company's marketing department you are invited by the Marketing Director to lead their positioning activities. Although you are the only candidate, the Marketing Director asked you to complete a number of tasks which will help justify your appointment at the next meeting of the Board of Directors." For intrinsic reward, the scenario is repeated but offers no incentive. Background information about the focal and competitor companies follows, along with a request that the respondents recommend an appropriate (to the focal company) positioning strategy using the typology in Kalafatis et al. (2000). This typology was selected for use here because its explanatory relevance was tested in a similar domain.

Next, the respondents were requested to complete two tasks. The text "your answers will help the Board of Directors confirm the decision to appoint you to the post" preceded each task to indicate that performance acts as a qualifier to justify the appointment. Task one involves indicating which of the positioning strategies presented earlier relates to Dell, Nike, Rolex, Kellogg's, and Budweiser (multiple use of a strategy is allowed). Task two entails matching mission statements extracted from the respective web pages of Microsoft, Facebook, Google, Amazon, and Southwest Airlines (each statement allocated to only one company). Lack of control over the respondents' professional background and working environment predicates the choice of companies (i.e., well-known rather than specific to building and allied sectors). The underlying assumption is that marketing directors should 
possess knowledge and appreciation beyond the market or sector they operate in. As McGrath (2016) states, "but at the core, running a successful enterprise requires a basic foundation which business leaders must possess. These core competencies generally allow for successful CEOs to pivot from one industry to another." In line with Crowe and Higgins (1997), questions related to interest and mood close the survey. A total of 78 usable replies were obtained: $46 \%$ were classified as top-level or senior management/executive, $28 \%$ as middlelevel managers, and $26 \%$ as first-level managers.

Measurement and measures - The Crowe and Higgins (1997) scale measures mood, while an abridged version of the locomotion and assessment scale by Kruglanski et al. (2000) (six rather than twelve items for each of the two dimensions) provides a metric for regulatory mode. The inclusion of timing controls in each question allows for the measurement of time spent by respondents on each section of the survey. Therefore, rather than using subjective measures, involvement is operationalized as time spent: (a) reading the information about the focal and competitor companies, (b) reviewing the positioning strategies, and (c) completing the two tasks. Interest is measured using the two-item scale from Pierro et al. (2006b).

\section{Study 1 - Results}

Given the small sample sizes and predictive orientation, analysis is carried out using Partial Least Squares, and specifically SmartPLS v 3.2.7 (Ringle et al., 2017). Statistical inferences are made through bootstrapping with 5,000 subsamples.

Measurement (outer) model - Table 1 shows that Cronbach's $\alpha$ and CR values greater than 0.70 , and AVE indices exceeding 0.50 provide confirmation of the psychometric properties of the scales.

[Insert Table 1 here] 
Involvement and motivation - Results in Figure 1 support the hypothesized positive impact of assessment orientation on involvement for two of the three measures of involvement: time spent considering the positioning strategies $(\beta=.345, p<.001)$ and time completing the two tasks $(\beta=.324, p<.05)$. Although we expected to find a negative relationship between locomotion orientation and involvement, the results are similar to assessment orientation (i.e., the relationship is positive $[\beta=.324, p<.05]$ and time spent completing the two tasks $[\beta=$ $.282, p<.05])$. Therefore, the results offer qualified support but also raise questions about the directionality of $\mathrm{H}_{1}$. Neither interaction terms are significant determinants of involvement; hence, the results do not support $\mathrm{H}_{2}$.

On the other hand, we find support for $\mathrm{H}_{3}$; the interaction effects are significant $\left(\beta_{\text {locomotion*task motivation }}=.209, p<.05 ; \beta_{\text {assessment*task motivation }}=.327, p<.01\right)$ and the patterns in the figure are in line with expectations. The effects of mood at the start or end of the survey are not significant. The explanatory power of the model is low for involvement $\left(\mathrm{R}^{2}\right.$ companies $=$ $\left..10, \mathrm{R}_{\text {strategies }}=.11 ; \mathrm{R}_{\text {tasks }}^{2}=.12\right)$, and weak-to-moderate for interest $\left(\mathrm{R}^{2}\right.$ interest $\left.=.34\right)$.

[Insert Figure 1 here]

\section{Likelihood of Changing a Recommended Positioning Strategy: Regulatory Mode, Leadership Style, and Market Feedback}

In addition to involvement and interest, this study examines drivers that encourage change in recommended positioning strategies. Higgins et al. (2003, p. 295) state that "the essential nature of locomotion from a motivational perspective involves simply moving away from a current state with no particular destination or direction in mind.” Pierro et al. (2006b, p. 356) add, "Thus the main concern of persons high on the locomotion direction dimension is simply 
to 'move' in an experiential or psychological sense." The implication is that, if offered the opportunity to change their recommendation, locomotors are likely to do so in order to "satisfy" their need for movement or change. Risk-taking and the ability to deal with negative outcomes are inherent in positioning decision making, especially those related to change (Koch \& Gyrd-Jones, 2019). Correspondingly, Panno et al. (2015) and Pierro et al. (2018) report positive associations among locomotion orientation, risk-taking, and regret. These results are in line with locomotors' tendency towards change and lead to the following hypothesis:

$\mathrm{H}_{4}$ : Locomotion orientation is positively related to the likelihood of changing the recommended positioning strategy.

Assessment "constitutes the comparative aspect of self-regulation concerned with critically evaluating entities or states, such as goals or means in relation to alternatives in order to judge relative quality" (Kruglanski et al., 2000, p. 794). Seeking to avoid making a mistake, assessors will refrain from initiating change until they are able to fully evaluate the outcome of their original decision, which can be affected only in the presence of full information. A lack of complete information makes change a high-risk decision, and Panno et al. (2015) find a negative association between assessment orientation and risk-taking. In addition, on the premise that change often lacks a clear or dominant alternative option, Scholer and Higgins (2012) provide empirical evidence to support the hypothesis that “increased assessment motivation during deliberation could even make deliberation less effective in instigating change" (p. 116). Therefore, the expectation is that assessors will be reluctant (i.e., will have a low likelihood) to accept an invitation to change an original decision. However, considerations related to the likelihood of changing an originally recommended positioning strategy can lead to inertia and the possibility of missing an opportunity (Zhang et al., 2016), neither of which are necessarily desirable traits in 
managerial decision making. Therefore, we propose that the coexistence of these conflicting forces imposes opposing directional effects and accordingly hypothesize that:

$\mathrm{H}_{5}$ : There is no significant relationship between assessment orientation and the likelihood of changing a recommended positioning strategy.

Although locomotion and assessment are considered to be independent (i.e., orthogonal) orientations, Pierro et al. (2012b, p. 250) state that "Optimal self-regulation should usually utilize both modes... 'Going in the right direction' requires that locomotion and assessment work together." Evidence in Pierro et al. (2012c), Kruglanski et al. (2013), and Pierro et al. (2018) supports the proposed complementarity of the two regulatory mode orientations. In B2B literature, studies by Jasmand et al. (2012), Sok et al. (2016), and Vieira et al. (2019) report significant effects of the interactions between the two orientations on salesforce behavior. Given the behavioral nature of changing a recommended strategy, we find the arguments in Vieira et al. (2019) convincing in terms of the moderating effects of assessment on the functional relationship between locomotion and the likelihood to change a recommended positioning strategy. Guided by "locomotion [orientated managers] ... can benefit from high levels of assessment that help a salesperson make the right decision" (Vieira et al., 2019, p. 1817). Therefore, we hypothesize that:

$\mathrm{H}_{6}$ : The positive relationship between locomotion orientation and the likelihood of changing the recommended positioning strategy is amplified at higher levels of assessment orientation.

Managerial decision-making takes place within an organizational environment and therefore is contingent on the motivational effects of leadership style (i.e., the style of a supervisor or line manager). Several studies reveal the relevance of leadership style in B2B marketing. At the strategic level, Lindgreen et al. (2009) show that transformational style has 
a positive impact on interaction and network marketing while transactional leadership is associated with database and network marketing. Izquierdo et al. (2015) demonstrate that transformational leadership leads to greater cost efficiency and supply chain coordination, while Inyang et al. (2018) find that, compared to transactional leadership, transformational leadership has a greater impact on salespeople's strategy implementation behavior.

Furthermore, Varela et al. (2019) report that salespeople's performance increases under a servant leadership style. In addition, Luu (2020, p. 95) establishes a "positive relationship between authentic leadership and sales employees' customer-orientated OCB (organization citizenship behavior) and service recovery performance." At the same time, Pierro et al. (2009, p. 612) explain the relevance of leadership style in RMT, noting that "Although individuals themselves often determine how they pursue a goal, and when they do... it is not always the case that individuals determine how they pursue a goal. Other people with power over them can determine how they pursue a goal.” Kruglanski et al. (2010, p. 391) add that "Just as locomotion and assessment are associated with preferred decision-making strategies, they should relate to preferences for different styles of leadership, with assessors preferring those that allow for much critical thought on the part of employees, and locomotors preferring those that allow for swift and efficient movement through objectives." Associating "forceful" leadership with a preference for direct and instant action and "advisory" leadership as a preference for discussion and dialogue, Kruglanski et al. (2010) demonstrate that locomotors prefer forceful leadership styles and assessors prefer advisory leadership styles. Congruence or fit is also inherent in Benjamin and Flynn (2006), who report that transformational leadership (i.e., those associated with change) results in higher motivation and evaluation for employees high in locomotion. Hamstra et al. (2014) report that performance increases when locomotion- (assessment) orientated individuals work under a forceful (advisory) leadership style. Forceful leadership is compatible with locomotors' high 
levels of task involvement and focuses on intrinsic benefits, while advisory leadership is compatible with assessors' concern with extrinsically derived social comparisons (Pierro et al., 2018). The following hypothesis reflects the idea that, when invited to change their recommended positioning strategy, managers are more likely to acquiesce when the request is instigated by a line manager whose leadership style aligns with their regulatory mode.

$\mathrm{H}_{7}$ : For managers with higher locomotion (assessment) orientation, the likelihood to change a recommended positioning strategy is higher when invited to do so by a line manager with a forceful (advisory) leadership style.

Reflecting the external crisis impetus for change (Koch \& Gyrd-Jones, 2019), we introduce market feedback to account for the impact of situational factors. Like leadership, the majority of B2B marketing research relates to a company's sales force. Chakrabarty et al. (2008), Srivastava and Rangarajan (2008), Hartmann and Rutherford (2015), and Gabler et al. (2017) report differential effects of positive and negative feedback. The former is a significant determinant while the latter has no impact on salespeople's satisfaction, job involvement, performance, and effort. Lin (2017) finds that positive and negative personfocused feedback by sales managers has significant positive effects on, correspondingly, salespeople's performance-prove and performance-avoid goal orientations. These findings are particularly relevant to this study because performance-prove and performance-avoid map respectively to the promotion and prevention orientations of the RMT, which reflects strategic orientations of self-regulation.

In addition, we identify two studies that focus on organizational feedback. Considering organizational performance feedback as a "discrepancy between the buyer's performance and its aspiration level," Yang et al. (2017, p. 107) state that feedback "signals decision makers whether their past routines and practices are effective or not ... performance feedback will trigger decision makers' searching behavior and change their risk tolerance.” Their study 
demonstrates a significant relationship between performance feedback and a firm's supplier selection.

Feedback is a crucial component of RMT as well. Amato et al. (2017) state that managerial ideas, decisions, or choices — especially those at the initial stage of a process — are often altered or refined in light of feedback, and Wytykowska and Gabińska (2015) add that one form of feedback is information regarding performance, and by extension, the likelihood of success. Elaborating on the concepts of self-focus, self-evaluation, regret, and counterfactual thinking, De Carlo et al. (2014) develop arguments in terms of the nature of interactions between the two regulatory mode orientations and feedback. Locomotors are unlikely to dwell on negative feedback but are likely to see new ways to move forward; positive feedback enhances their convictions and in turn diverts their attention to new challenges. Although assessors share the same pattern as locomotors when feedback is positive, negative feedback may lead an individual to become stuck in a repeated pattern of worrying without ever moving forward (i.e., "paralysis by analysis" or becoming "lost in thought") (Pierro et al., 2018, pp. 252 - 253). We therefore propose that:

$\mathrm{H}_{8 \mathrm{a}}$ : For managers with higher locomotion orientation, the likelihood of changing a recommended positioning strategy is higher (lower) when market feedback is negative (positive).

$\mathrm{H}_{8 \mathrm{~b}}$ : For managers with higher assessment orientation, market feedback has no effect on the likelihood of changing a recommended positioning strategy.

\section{Study 2 - Method}

Design, procedure, data collection, and sampling - The above hypotheses are tested using a 2 (market feedback) x 5 (leadership style) experimental design. Market feedback is either 
positive ("Twelve months later, you meet with the company's board. The board is pleased because the company recorded a $15 \%$ share gain from its two main competitors.") or negative ("Twelve months later, you meet with the company's board. The board is concerned because the company recorded a $15 \%$ share loss to its two main competitors.”) Decisions about percentage change are based on the work of Keeling et al. (2013). The five leadership styles under which a manager makes positioning decisions (i.e., rewards, coercive, legitimate, expert, and referent [see Appendix B]) originate from Kruglanski et al. (2007).

Consistent with Study 1, the survey begins with questions about mood and regulatory mode. The participants are presented with background information about the three companies; their role is explained, and they are asked to recommend a positioning strategy. Next, respondents are randomly exposed to one of the experimental conditions and asked to indicate the likelihood of changing their recommendation following discussions with their line manager. Consider this example (positive gain and coercive power): "We are now twelve months later and the company recorded a $15 \%$ share gain from its two main competitors. Your line manager, a person who influences whether you get a pay rise, promotion, or special benefits, calls you to discuss the results. The message at the meeting is that although the results are positive there is scope for adjusting or even changing the [recommended positioning strategy.]" The survey closes with mood-related questions. Applying the same data collection and sampling procedures as in Study 1 results in 119 usable replies equally distributed between the treatments. The managerial profile of the respondents is $57 \%$ toplevel, 29\% middle-level, and 14\% first-level.

Measurement and measures - The same scales as those in Study 1 are used to measure mood, locomotion, and assessment, while a single-item, five-point scale ranging from "extremely likely" to "extremely unlikely" measures the likelihood of changing the initially recommended positioning strategy. 


\section{Study 2 - Results}

The adopted scales meet accepted psychometric benchmarks (Table 2).

[Insert Table 2 here]

For the analysis, following Kruglanski et al. (2007), we classified expert and referent styles as "advisory" and reward, coercive, and legitimate styles as "forceful." The results in Figure 2 support both $\mathrm{H}_{4}$ and $\mathrm{H}_{5}$. The functional relationship between locomotion and the likelihood of changing the recommended positioning strategy is significant $(\beta=.185, p<.05)$, whereas the corresponding relationship for assessment is not significant $(\beta=.090, \mathrm{~ns})$. In support of $\mathrm{H}_{6}$, the interaction of the two orientations is significant $(\beta=.305, p<.05)$ and the related pattern supports the hypothesized amplification effect of assessment. None of the interaction effects between the regulatory modes with market feedback or leadership style are significant; this supports $\mathrm{H}_{8 \mathrm{~b}}$ but not $\mathrm{H}_{7}$ or $\mathrm{H}_{8 \mathrm{a}}$. Mood, at the end of the survey, has no significant impact on the dependent variable. With an $\mathrm{R}^{2}=.24$ the explanatory power of the model is weak.

\section{[Insert Figure 2 here]}

\section{Discussion}

Expanding on rational and economic perspectives, Bagozzi (2006) proposed self-regulation as an additional behavioral influence in the B2B domain. Bagozzi (2006) developed arguments regarding the relevance of emotional aspects of self-regulation and subsequent studies examined the role of emotions, especially in the formation of business relationships and the behavior of salespeople (e.g., Limbu et al., 2016; Briggs et al., 2018; Delpechitre et al., 2019). Self-regulation is also the theoretical platform of this study. However, our focus is 
on its motivational (rather than emotional) aspects, and we are specifically interested in selfregulation mechanisms that underpin managerial decision making.

Applying the locomotion and assessment orientations from RMT, this study investigates the role that managers' preference for action plays in B2B positioning decision making. Results from two experiments highlight the relevance of goal-pursuit approaches to positioning decisions and provide novel insights. First, contrary to expected differences between motivational approaches, the results reveal positive associations among both critical evaluation (assessment orientation), preference for moving forward (locomotion), and involvement. Second, the introduction of the type of motivation (expected rewards) as a moderator helps explain differences in levels of interest in positioning decision making among the choice of approaches to the pursuit of goals. Finally, analysis establishes independence between regulatory mode orientation and contextual factors on the likelihood of changing the recommended positioning strategy. Even though our focus is different from Jasmand et al. (2012), Sok et al. (2016), and Vieira et al. (2019), the findings reinforce the relevance of RMT in explaining B2B marketing practice and extend the application of the theory from salesforce behavior to managerial decision making and specifically those related to corporate positioning. In addition, the results highlight the importance of contextual considerations and structural parameters when testing the precepts of RMT.

\section{Theoretical implications}

The results indicate a positive relationship between both orientations and involvement (time expended) when recommending a positioning strategy. The relationship between assessment orientation and involvement is consistent with expectations and the results reported in, among others, Amato et al. (2014) and Kruglanski et al. (2016). On the other hand, the positive 
relationship between locomotion orientation and involvement is unexpected. Acknowledging the need for further examination of the functional relationship between regulatory mode and risk (see Panno et al. 2014 \& 2015), we propose that risk-specifically, the implied consequences of recommending an inappropriate positioning strategy—is the underlying reason for this finding. We suggest that under conditions of high risk and the associated substantial threat to managers' professional and financial status, the two regulatory modes converge in terms of time invested in decision making. To minimize such risks, and in the absence of a clear or ideal solution to positioning-related problems, a manager's inclination is to engage in extended cognitive effort that involves investing more time in related considerations. Further, the risks related to recommending a positioning strategy in an industrial context created a situational environment that aroused an assessment state amongst the participants (Mannetti et al., 2009; Kruglanski et al., 2010) due to the requirement for accuracy in the decision-making process (Mauro et al., 2009). Accepting that positioning decisions include elements of financial responsibility, these findings align with the dominance of assessment in the situational affordance list in Higgins et al. (2003).

Although not expressed as formal hypotheses, the significant direct effects of task motivation on involvement with and interest in the process of recommending a positioning strategy are consistent with Bande et al. (2016) and Rajabi et al. (2018). The positive signs of both relationships imply that, irrespective of orientation, intrinsic rewards lead to higher involvement and interest. However, the generalizability of this finding should be tempered by the significance of the interaction effects. The differential moderating role of task motivation (type of reward) on involvement with and interest in positioning deliberations provides a new perspective and specifically highlights the relevance of the underlying nature of cognitive elaboration. Involvement with positioning decisions is externally focused, representing active participation and interaction with organizational colleagues. Irrespective of regulatory mode 
or expected rewards, managers must demonstrate active leadership and legitimize their authority by explicitly demonstrating involvement. These considerations suppress variation and lead to no evidence of significant interaction effects between regulatory mode and task motivation; involvement with positioning decisions is a managerial requirement rather than a personal choice. Rather than contradicting the literature (Kruglanski et al., 2000; Pierro et al., 2006b; Bélanger et al., 2015) the above explanation should be considered as an illustration of the importance of including contextual variables in RMT studies. To the above, contextualization of adopted measures is added as a possible explanation. This study uses actual time spent on deliberations and/or the completion of tasks as the dependent variable, while Pierro et al. (2006a and b) employ self-reporting operationalizations, Pierro et al. (2006a) measure respondents' general tendency for involvement, and Pierro et al. (2006b) assess respondents' intention to commit effort. Similar to issues raised in the application of the Theory of Planned Behavior, the results could be confounded under conditions of weak correspondence between a measure and its contextual application (Ajzen, 2006). Compared to involvement, interest in positioning decisions has a predominantly personal meaning rather than being a shared experience, and is driven by intellectual curiosity; therefore, task motivation in the form of rewards or incentives becomes active. Consistent with the literature (see Pierro et al., 2006b; Giacomantonio et al., 2013), assessors' interest is higher when task motivation is extrinsic, while intrinsic task motivation increases locomotors' interest. The reward offers the participants a means of enhancing their professional status and therefore affords them the opportunity to meet their need for social comparison (Kruglansi et al., 2010, p. 387).

The significant impact of the direct effects of locomotion but not of assessment on the likelihood of changing a recommendation is in line with RMT. Offering locomotionorientated managers the opportunity to change their recommended positioning strategy 
sustains their need for movement from one state to another, even in the absence of a "clearly superior alternative-state" (Scholer \& Higgins, 2012, p. 116). On the other hand, the same opportunity offered to assessors "may simply leave some individuals spinning their wheels" (Scholer \& Higgins, 2012, p. 116) due to lack of or difficulties in obtaining sufficient information with which to carry out a detailed evaluation. The significant moderating effect of assessment on the functional relationship between locomotion and the likelihood of changing a recommended positioning strategy accords with the notion of complementarity between the two orientations (Pierro et al., 2012b; Kruglanski et al., 2013). In support of Jasmand et al. (2012), Sok et al. (2016), and Vieira et al. (2019), we find that assessment amplifies the positive effects of locomotion on the likelihood of changing a recommended strategy. Similar to salespeople, locomotors find the analytical and critical elements of assessment helpful in verifying their inclinations toward changing their initial recommendations.

Contrary to reported evidence regarding the influence of leadership style (e.g., Benjamin \& Flynn, 2006; Kruglanski et al., 2007), the interaction effects between regulatory mode and leadership style on the likelihood of changing a recommended positioning strategy are not significant. This lack of convergence with the literature is attributed to differences in the dependent variable which, in this study, is external decision making; by contrast, in Benjamin and Flynn (2006), the dependent variable is motivation, in Kruglanski et al. (2007) the dependent variable is job satisfaction, and in Pierro et al. (2012a) and Hamstra et al. (2014), the dependent variable is performance, all of which are internal. Dissimilarities in focal interest limit direct comparison between the results of this study and those in B2B marketing literature. Nevertheless, the question of why leadership style has no effect on the likelihood of changing a recommended positioning strategy but does affect other marketing activities remains (although not a formal hypothesis, the direct effects of leadership style on 
the likelihood of changing a recommended strategy are not significant). We refer to Koch and Gyrd-Jones (2019, p. 51), and more specifically to their conclusion that corporate brand positioning is "a complex, episodic, and dynamic process," and that "positioning and repositioning are essentially change management phenomena." The implication is that strategic changes in organizations operating in industrial markets involve input from a number of managers (e.g., co-managing) rather than being the domain of a single individual (see Wagner \& Eggert, 2016). Therefore, an individual manager's role in repositioning is limited compared to the corresponding influence in salesforce related decisions (see Inyang et al., 2018; Varela et al., 2019; Luu, 2020).

Market feedback has no impact on the likelihood of changing a recommended positioning strategy for both locomotors and assessors. The results for assessors are congruent, while those for locomotors diverge from expectations and, importantly, indicate independence between regulatory mode orientation and market feedback. The significant relationship between market feedback and the likelihood of changing a recommended positioning strategy (not a formal hypothesis) is consistent with research in strategic management (Boeker, 1997; Tarus \& Aime, 2014) and provides confidence in the independence conclusion.

\section{Managerial Implications}

The overriding finding that preference for action (regulatory mode) plays a significant role in the positioning process has important managerial implications. The positive relationships between both modes, which involve time spent considering different positioning strategies and carrying out positioning-related tasks, are promising because they suggest that engagement with these two facets of positioning takes place irrespective of personal 
preference for action. We propose that the centrality of positioning decision making to marketing practice acts as a halo effect that outweighs personal preferences. Therefore, rather than stimulating the self-motivation skills of those involved in positioning decision making, senior management should emphasize the strategic importance of positioning, including corporate confidence in successful positioning as a significant driver of company performance. Given the dynamic and multi-level nature of positioning (Koch \& Gyrd-Jones, 2019), it is the senior management's responsibility to ensure appreciation of the risks related to inefficient positioning decisions and to engender a corporate culture that values accuracy and precision. On the other hand, the lack of a significant relationship between the two types of regulatory mode and time spent evaluating the focal company and its competitors is a concern. Developing a clear understanding of the competitive landscape is a fundamental facet of positioning. We therefore suggest regular application of mechanisms, methodologies (e.g., positioning mapping), and protocols designed to uncover the differentiating characteristics of the companies in a specific market. The results of such activities should be key inputs to scenario planning activities.

This study offers evidence showing significant relationships between self-regulation, interest, and task performance (see O'Keefe \& Linnenbrink-Garcia, 2014). Our findings suggest that intrinsic and extrinsic rewards correspondingly moderate the relationships among locomotion, assessment, and interest in positioning-related activities. Given the differential behavior of the regulatory modes, determining an individual's mode (either through formal tests or informal appraisal meetings) is important in determining the appropriate form of rewards. Allocating activities that engender curiosity and align with a desire for new experiences will enhance locomotors' interest in positioning. Such activities could take the form of discovering new information, applying novel analytical techniques, or encouraging the adoption of emerging approaches to positioning. Assessors' preference for extrinsic 
rewards can take the form of monetary rewards and professional advancement. However, non-financial rewards - such as continuous positive feedback that highlights an individual's contribution to the team or assigning leadership roles in the positioning activities of the company — could also be effective in increasing interest.

If a firm wishes to reposition or modify a previously established positioning strategy, our study reveals that locomotors are more likely to make such changes and therefore should lead related activities. This recommendation does not diminish the role and importance of assessors. On the contrary: we propose assembling a team that comprises both orientations. In other words, following Pierro et al. (2018), we suggest that change can be best achieved through regulatory mode conjunction, i.e., a complementary combination of inputs by assessors and locomotors. Locomotors provide the urgency and forward impetus which is complemented by the detailed assessment and evaluation provided by assessors. Senior management should provide a clear delineation of tasks and demarcation of positioningrelated activities and should present the team with a clear view of how inputs provided by locomotors and assessors come together to propose an effective plan.

We find that, for both assessors and locomotors, neither their line manager's leadership style nor market feedback affect the likelihood of changing a recommended positioning strategy. These results lead us to suggest that the strategic importance of modifying a positioning strategy restrains or subdues the role of senior management. We therefore suggest that senior management should provide evidence-based rationales and explanations that justify a request for changing an established positioning strategy. 


\section{Limitations and directions for future research}

This study has limitations, and the reported findings provide opportunities for future research. The stability of the identified relationships across different positioning strategies and industrial domains should be established. Cross-examination of the identified patterns under conditions of induced regulatory modes will provide contextual verification. By focusing on RMT, other relevant constructs—-such as decision-making unit (DMU) structure, interorganizational conflict, market structures, and economic conditions (e.g., turbulence and uncertainty) — are omitted. The interface and reconciliation of differing regulatory modes by members of the DMU offers another research avenue. Given the proximity of positioning to corporate image and branding, related constructs should also be included in future research.

The cross-sectional nature of this study must be acknowledged. To that end, expanding the methodology to include dynamic competitive behaviors as part of a longitudinal design will provide additional insights. Obtaining replies exclusively from marketing managers and increased sample sizes are additional methodological improvements.

\section{Appendices}

Appendix A: Description of focal company and its two main competitors (names are aliases)

Focal company $-<$ Company name $>$ was established in 1757 and has been under the continuous management of the <name $>$ family. The company operates under its own name supplying trade and has a nationwide distribution base. It specializes in timber and woodbased sheet materials with a small assortment of supplementary building materials.

Competitor 1 - With over 600 branches across the country <company name $>$ is a supplier of a comprehensive range of both timber and building materials. Customers range from builders to DIY enthusiasts. In addition, it offers specialist landscaping, tool hire, design, and installation of kitchen and bathroom services. Positioning strategy: Range of offerings. 
Competitor $2-<$ Company name $>$ is a diverse company formed through mergers and acquisitions of small local companies. Although it has extensive nationwide coverage, it operates under a variety of brand names, each focusing on a specific sector of the construction industry. Positioning strategy across all brand names: Ease of doing business.

\section{Appendix B: Leadership style/social power}

Reward - a person who influences whether you get a pay raise, promotion, or special benefits, calls you to discuss the results.

Coercive - a person who is making your job difficult, has made things unpleasant for you, and makes your working environment distasteful, calls you to discuss the results.

Legitimate - a person who makes you feel that you should satisfy your job requirements, gives you a feeling that you have responsibilities to fulfill, and makes you recognize that you have tasks to accomplish, calls you to discuss the results.

Expert - a person who gives you good marketing suggestions, provides you with sound jobrelated advice, and shares with you his/her considerable experience, calls you to discuss the results.

Referent - a person who makes you feel valued, approves of you, and makes you feel important, calls you to discuss the results.

\section{References}

Ajzen, I. (2006), “Constructing a TpB questionnaire: Conceptual and methodological considerations", https://pdfs.semanticscholar.org/0574/b20bd58130dd5a961fla2db10fd1fcbae95d.pdf.

Amato, C., Baldner, C.S., Pierro, A. and Kruglanski, A.W. (2019), “Tempus Divitiae: Locomotion orientation and evaluation of time as a precious resource", Time \& Society, Vol. 28 No. 3, pp. 1105-1123. 
Amato, C., Baron, R.A., Barbieri, B., Bélanger, J.J. and Pierro, A. (2017), "Regulatory modes and entrepreneurship: The mediational role of alertness in small business success", Journal of Small Business Management, Vol. 55 No. 51, pp. 27-42.

Amato, C., Pierro, A., Chirumbolo, A. and Pica, G. (2014), "Regulatory modes and time management: How locomotors and assessors plan and perceive time", International Journal of Psychology, Vol. 49 No. 3, pp. 192-199.

Amonini, C., McColl-Kennedy, J.R., Soutar, G.N. and Sweeney, J.C. (2010), "How professional service firms compete in the market: An exploratory study", Journal of Marketing Management, Vol. 26 No. 1-2, pp. 28-55.

Bagozzi, R.P. (2006), “The role of social and self-conscious emotions in the regulation of business-to-business relationships in salesperson-customer interactions, Journal of Business \& Industrial Marketing, Vol 21 No 7, pp. 453-457.

Bande, B., Fernández-Ferrín, P., Varela-Neira, C. and Otero-Neira, C. (2016), "Exploring the relationship among servant leadership, intrinsic motivation and performance in an industrial sales setting”, Journal of Business \& Industrial Marketing, Vol. 31 No. 2, pp. 219-231.

Bélanger, J.J., Pierro, A., Kruglanski, A.W., Vallerand, R.J., De Carlo, N. and Falco, A. (2015), "On feeling good at work: The role of regulatory mode and passion in psychological adjustment", Journal of Applied Social Psychology, Vol. 45, pp. 319329.

Benjamin, L. and Flynn, F.J. (2006), “Leadership style and regulatory mode: Value from fit?" Organizational Behavior and Human Decision Processes, Vol. 100 No. 2, pp. 216-230.

Boeker, W. (1997), "Strategic change: The influence of managerial characteristics and organizational growth", Academy of Management Journal, Vol. 40 No. 1, pp. 152-170. 
Briggs, E., Kalra, A. and Agnihotri, R. (2018), "Contrasting effects of salespeople's emotion appraisal ability in a transaction-oriented environment", Journal of Business \& Industrial Marketing, Vol. 33 No. 1, pp. 84-94.

Carvera, A., Mollá, A. and Sánchez, M. (2001), “Antecedents and consequences of market orientation in public organisations", European Journal of Marketing, Vol. 35 No. 11/12, pp. 1259-1286.

Chakrabarty, S., Oubre, D.T. and Brown, G. (2008), "The impact of supervisory adaptive selling and supervisory feedback on salesperson performance”, Industrial Marketing Management, Vol. 37, pp. 447-454.

Chen, C.Y., Rossignac-Milton, M. and Higgins, E.T. (2018), "Feeling distressed from making decisions: Assessors' need to be right", Journal of Personality and Social Psychology, Vol. 115 No. 4, pp. 743-761.

Crowe, E. and Higgins, E.T. (1997), "Regulatory focus and strategic inclinations: Promotion and prevention in decision-making”, Organizational Behavior and Human Decision Processes, Vol. 69 No. 2, pp. 117-132.

Davis, D., Morris, M. and Allen, J. (1991), "Perceived environmental turbulence and its effect on selected entrepreneurship, marketing, and organizational characteristics in industrial firms", Journal of the Academy of Marketing Science, Vol. 19 No. 1, pp. 43-51.

De Carlo, N.A., Falco, A., Pierro, A., Dugas, M., Kruglanski, A.W., \& Higgins, E.T. (2014), "Regulatory mode orientations and well-being in an organizational setting: The differential mediating roles of workaholism and work engagement", Journal of Applied Social Psychology, Vol. 44, pp. 725-738.

Deci, E. L., Koestner, R. and Ryan, R. M. (2001), "Extrinsic rewards and intrinsic motivation in education: Reconsidered once again”, Review of Educational Research, Vol. 71, pp. $1-27$. 
Deci, E.L. and Ryan, R.M. (1985), Intrinsic Motivation and Self-Determination in Human Behavior, Plenum: New York.

Delpechitre, D., Rutherford, B. and Comer, L. (2019), "The importance of customer's perception of salesperson's empathy in selling", Journal of Business \& Industrial Marketing, Vol. 34 No. 2, pp. 374-388.

Diwan, S.P. and Bodla, B.S. (2011), "Development of empirically based customer-derived positioning typology in the automotive industry", Journal of Strategic Marketing, Vol. 19 No. 6, pp. 531-550.

Gabler, C.B; Agnihotri, R. and Itani, O.S. (2017), "Can salesperson guilt lead to more satisfied customers? Findings from India”, Journal of Business \& Industrial Marketing, Vol. 32 No. 7, pp. 951-961.

Garcia, D., Jimmefors, A., Mousavi, F., Adrianson, L., Rosenberg, P. and Archer, T. (2015), "Self-regulatory mode (locomotion and assessment), well-being (subjective and psychological), and exercise behavior (frequency and intensity) in relation to high school pupils' academic achievement", PeerJ 3:e847, https://doi.org/10.7717/peerj.847.

Giacomantonio, M., Mannetti, L. and Pierro, A. (2013), "Locomoting toward well-being or getting entangled in a material world: Regulatory modes and affective well-being”, Journal of Economic Psychology, Vol. 38 No. October, pp. 80-89.

Hamstra, M.R., Orehek, E. and Holleman, M. (2014), "Subordinate regulatory mode and leader power: Interpersonal regulatory complementarity predicts task performance”, European Journal of Social Psychology, Vol. 44 No. 1, pp. 1-6.

Hartmann, N.N. and Rutherford, B. (2015), "Psychological contract breach's antecedents and outcomes in salespeople: The roles of psychological climate, job attitudes, and turnover intention", Industrial Marketing Management, Vol. 51, pp. 158-170 
Higgins, E.T., Kruglanski, A.W. and Pierro, A. (2003), "Regulatory mode: Locomotion and assessment as distinct orientations", In: M.P. Zanna (Ed.), Advances in Experimental Social Psychology, Vol. 35, pp. 293-344.

Hooley, G., Greenley, G., Fahy, J. and Cadogan, J. (2001), “Market-focused resources, competitive positioning and firm performance", Journal of Marketing Management, Vol. 17 No. 5-6, pp. 503-520.

Inyang; A.E., Raj; A., \& Munoz, L. (2018), “The role of manager leadership style in salesperson implementation of sales strategy: a contingency perspective", Journal of Business \& Industrial Marketing, Vol. 33 No. 8, pp. 1074-1086.

Iyer, P., Davari, A., Zofagharian, M. and Paswan, A. (2019), "Market orientation, positioning strategy and brand performance”, Industrial Marketing Management, Vol. 81, pp. 1629.

Izquierdo, C.C., Samaniego, M.J.G. and Cabezudo, R.S.J. (2015), "How strategic purchasing orientation and transformational leadership impact performance: The mediating role of information and communication technologies", Journal of Business-to-Business Marketing, Vol. 22 No. 4, pp. 269-292.

Jalkala, A.M. and Keränen, J. (2014), "Brand positioning strategies for industrial firms providing customer solutions", Journal of Business \& Industrial Marketing, Vol. 29 No. 3, pp. 253-264.

Jasmand, C., Blazenic, V. and de Ruyter, K. (2012), “Generating sales while providing service: A study of customer service representatives' ambidextrous behavior", Journal of Marketing, Vol. 76, No. 1, pp. 20-37.

Kalafatis, S.P., Tsogas, M.H. and Blankson, C. (2000), "Positioning strategies in business markets”, Journal of Business \& Industrial Marketing, Vol. 15 No. 6, pp. 416-437. 
Keeling, D.I., Daryanto, A., de Ruyter, K. and Wetzels, M. (2013), “Take it or leave it: Using regulatory fit theory to understand reward redemption in channel reward programs”, Industrial Marketing Management, Vol. 42 No. 8, pp. 1345-1356.

Koch, C.H. and Gyrd-Jones, R.I. (2019), “Corporate brand positioning in complex industrial firms: Introducing a dynamic, process approach to positioning”, Industrial Marketing Management, Vol. 81, pp. 40-53.

Köpetz, C.E., Lejuez, C.W., Wiers, R.W. and Kruglanski, A.W. (2013), “Motivation and selfregulation in addiction: A call for convergence", Perspectives on Psychological Science, Vol. 8 No. 1, pp. 3-24.

Korhonen-Sande, S. and Sande, J.B. (2016), "Improving customer knowledge transfer in industrial firms: how does previous work experience influence the effect of reward systems?” Journal of Business \& Industrial Marketing, Vol. 31 No. 2, pp. 232-246.

Kotler, P. and Armstrong, G. (2014), Principles of Marketing. Global Edition, $15^{\text {th }}$ ed., Pearson Prentice Hall: Upper Saddle River, NJ.

Kraus, S., Breier, M., Jones, P. and Hughes, M. (2019), “Individual entrepreneurial orientation and intrapreneurship in the public sector", International Entrepreneurship and Management Journal, Vol 15, pp. 1247-1268.

Kruglanski, A.W., Orehek, E., Higgins, E.T., Pierro, A. and Shalev, I. (2010), "Models of self-regulation: Assessment and locomotion as independent determinants in goalpursuit”, In: R. Hoyle (Ed.), Handbook of Personality and Self-Regulation (pp. 374402), Blackwell: Boston.

Kruglanski, A.W., Pierro, A. and Higgins, E.T. (2007), "Regulatory mode and preferred leadership styles: How fit increases job satisfaction”, Basic and Applied Social Psychology, Vol. 29 No. 2, pp. 137-149. 
Kruglanski, A.W., Pierro, A. and Higgins, E.T. (2016), "Experience of time by people on the go: A theory of the locomotion-temporality interface", Personality and Social Psychology Review, Vol. 20 No. 2, pp. 100-117.

Kruglanski, A.W., Pierro, A., Mannetti, L. and Higgins, T.E. (2013), “The distinct psychologies of "looking" and "leaping": Assessment and locomotion as the springs of action”, Social and Personality Psychology Compass, Vol. 7 No. 2, pp. 79-92.

Kruglanski, A.W., Thompson, E.P., Higgins, E.T., Atash., M.N., Pierro, A., Shah, J.Y. and Spiegel, S. (2000), "To 'do the right thing' or to 'just do it': Locomotion and assessment as distinct self-regulatory imperatives", Journal of Personality and Social Psychology, Vol. 79 No. 5, pp. 793-815.

Lewin, J.E. and Johnston, W.J. (1996), “The effects of organizational restructuring on industrial buying behavior: 1990 and beyond”, Journal of Business \& Industrial Marketing; Vol. 11 No. 6, pp. 93-111.

Limbu, Y., Jayachandran, C., Babin, B. and Peterson, R. (2016), "Empathy, nonverbal immediacy, and salesperson performance: the mediating role of adaptive selling behavior", Journal of Business \& Industrial Marketing, Vol. 31 No. 5, pp. 654-667.

Lindgreen, A., Palmer, R., Wetzels, M. and Antioco, M. (2009), “Do different marketing practices require different leadership styles? An exploratory study", Journal of Business \& Industrial Marketing; Vol. 24 No. 1, pp. 14-26.

Lin, Y-T. (2017), "Praise sales personnel for talent or effort? Person versus process-focused feedback, goal orientation and performance", Journal of Business \& Industrial Marketing, Vol. 32 No. 8, pp. 1073-1086.

Luu, T.T. (2020), “Linking authentic leadership to salespeople's service performance: The roles of job crafting and human resource flexibility", Industrial Marketing Management, Vol. 84, pp. 89-104. 
Makkonen, H., Saarikorpi, M. and Rajala, R. (2019), “A transition from goods-dominant to service-dominant exchange logic in a $\mathrm{B} 2 \mathrm{~B}$ relationship: A relationship positioning perspective”, Industrial Marketing Management, Vol. 81, pp. 65-77.

Mallin, M.L. and Ragland, C.B. (2017), "Power-base effects on salesperson motivation and performance: A contingency view", Journal of Business-to-Business Marketing, Vol. 24 No. 2, pp. 99-121.

Mannetti, L., Leder, S., Insalata, L., Pierro, A., Higgins, T. and Kruglanski, A. (2009), "Priming the ant or the grasshopper in people's mind: How regulatory mode affects inter-temporal choices”, European Journal of Social Psychology, Vol. 39, pp. 11201125 .

Mauro, R., Pierro, A., Mannettin, L., Higgins, T.E. and Kruglanski, A.W. (2009), "The perfect mix: Regulatory complementarity and the speed-accuracy balance in group performance", Psychological Science, Vol. 20 No. 6, pp. 681-685.

Mayo, M. and Mallin, M. (2014), “Antecedents and anticipated outcomes of superstitious behavior among professional salespeople”, Journal of Business \& Industrial Marketing, Vol. 29 No. 3, pp. 227-237.

McColl, R., Truong, Y. and La Ross, A. (2019), “Services guarantees as a base for positioning in B2B”, Industrial Marketing Management, Vol. 81, pp. 78-86.

McGrath, J. (2016). "How successful CEOs make the jump from industry to industry", https://www.entrepreneur.com/article/275370.

Mehta, R., Anderson, R.E. and Dubinsky, A.J (2000), "The perceived importance of sales managers' rewards: a career stage perspective", Journal of Business \& Industrial Marketing, Vol. 15 No. 7, pp. 507-524.

Nowlin, E., Walker, D., Deeter-Schmelz, D.R. and Haas, A. (2018), "Emotion in sales performance: affective orientation and need for cognition and the mediating role of 
motivation to work", Journal of Business \& Industrial Marketing, Vol. 33 No. 1, pp. 107-116.

O'Keede, P.A. and Linnenbrink-Garcia, L. (2014), “The role of interest in optimizing performance and self-regulation”, Journal of Experimental Social Psychology, Vol. 53, pp. 70-78.

Panda, S., Paswan, A.K. and Mishra, S.P. (2019), "Impact of positioning strategies on franchise fee structure", Industrial Marketing Management, Vol. 81, pp. 30-39.

Panno, A., Lauriola, M. and Pierro, A. (2015), "Regulatory mode and risk-taking: The mediating role of anticipated regret", PLoS ONE, Vol. 10 No. 11: e0143147, https://doi.org/10.1371/journal.pone.0143147.

Panno, A., Pierro, A. and Lauriola, M. (2014), “Self-regulation predicts risk-taking through people's time horizon", International Journal of Psychology, Vol. 49 No. 3, pp. 211 215.

Penttinen, E. and Palmer, J. (2007), “Improving firm positioning through enhanced offerings and buyer-seller relationships", Industrial Marketing Management, Vol. 36 No. 5, pp. $552-564$.

Pierro, A., Chernikova, M., Destro, C.L., Higgins, E.T. and Kruglanski, A.W. (2018), “Assessment and locomotion conjunction: How looking complements leaping... but not always", In: Advances in Experimental Sociology, Vol. 58 Chapter 5, pp. 243-299.

Pierro, A., Giacomantonio, M., Mannetti, L., Higgins, E.T. and Kruglanski, A.W. (2012a), “Leaders as planners and movers: Supervisors' regulatory modes and subordinates’ performance”, Journal of Applied Social Psychology, Vol. 42 No. 10, pp. 2564-2582.

Pierro, A., Giacomantonio, M., Pica, G., Kruglanski, A.W. and Higgins, E.T. (2011), “On the psychology of time in action: Regulatory mode orientations and procrastination", Journal of Personality and Social Psychology, Vol. 101 No. 6, pp. 1317-1331. 
Pierro, A., Giacomantonio, M., Pica, G., Kruglanski, A.W. and Higgins, E.T. (2013), "Locomotion and the preference for multi-tasking: Implications for well-being", Motivation and Emotion, Vol 37 No. 2, pp. 213-223.

Pierro, A., Kruglanski, A.W. and Higgins, E.T. (2006a), "Progress takes work: Effects of the locomotion dimension on job involvement, effort investment, and task performance in organizations", Journal of Applied Social Psychology, Vol. 36 No. 7, pp. 1723-1743.

Pierro, A., Kruglanski, A.W. and Higgins, E.T. (2006b), "Regulatory mode and the joys of doing: Effects of 'locomotion' and 'assessment' on intrinsic and extrinsic taskmotivation", European Journal of Personality, Vol. 20 No. 5, pp. 355-375.

Pierro, A., Pica, G., Giannini, A.M., Higgins, E.T. and Kruglanski, A.W. (2018), “Letting myself go forward past wrongs: How regulatory modes affect self forgiveness", PLoS ONE, Vol. 13 No. 3: e0193357, https://doi.org/10.1371/journal.pone.0193357.

Pierro, A., Pica, G., Mauro, R., Kruglanski, A. W., \& Higgins, E. T. (2012b), “How regulatory modes work together: Locomotion-assessment complementarity in work performance”, Testing, Psychometrics, Methodology in Applied Psychology, Vol. 19, pp. $247-262$.

Pierro, A., Presaghi, F., Higgins, E.T., Klein, K.M. and Kruglanski, A.W. (2012c), "Frogs and ponds: A multilevel analysis of the regulatory mode complementarity hypothesis", Personality and Social Psychology Bulleting, Vol. 38 No. 22, pp. 269-279.

Pierro, A., Presaghi, F., Higgins, T.E. and Kruglanski, A.W. (2009), "Regulatory mode preference for autonomy supporting versus controlling instructional styles", British Journal of Educational Psychology, Vol. 79 No. 4, pp. 599-615.

Pullins; E.B., Haugtvedt, C., Dickson, P., Fine, L. and Lewicki, R. (2000), “Individual differences in intrinsic motivation and the use of cooperative negotiation tactics", Journal of Business \& Industrial Marketing; Vol. 15 No. 7, pp. 466-478. 
Rajabi, R., Brashear-Alejandro, T. and Chelariu, C. (2018), "Entrepreneurial motivation as a key salesperson competence: Trait antecedents and performance consequences”, Journal of Business \& Industrial Marketing, Vol. 33 No. 4, pp. 405-416.

Ries, A. and Trout, J. (1986), Marketing Warfare, McGraw Hill: New York, NY.

Ringle, C.M., Wende, S. and Becker, J-M. (2017). SmartPLS 3. Bönningstedt: SmartPLS. Retrieved from http://www.smartpls.com.

Robbins, S.P. (1998), Organizational Behavior, $8^{\text {th }}$ ed., Prentice Hall, Upper Saddle River, NJ.

Rodríguez-Pinto., J., Rodríguez-Escudero, A.I. and Gutiérrez-Cillán, J. (2008), “Order, positioning, scope and outcomes of market entry", Industrial Marketing Management, Vol. 37 No. 2, pp. 154-166.

Scholer, A.A. and Higgins, E.T. (2012), “Commitment to change from locomotion motivation during deliberation", Motivation and Emotion, Vol. 36 No. 2, pp. 114-129.

Sok, K.M., Sok, P. and De Luca, L.M. (2016), “The effect of 'can do' and 'reason to' motivations on service-sale ambidexterity", Industrial Marketing Management, Vol. 55 , pp. $144-155$.

Srivastava, R. and Deva. R. (2008), "Understanding the salespeople's "feedback-satisfaction" linkage: what role does job perceptions play?", Journal of Business \& Industrial Marketing, Vol. 23 No. 3, pp. 151-160.

Syed, I. and Mueller, B. (2014), "Finding the passion to persevere: An exploration of the mechanisms by which passion fuels entrepreneurial grit", Frontiers of Entrepreneurship Research, Vol. 34 No. 6, Article 1.

Tarus, D.K. and Aime, F. (2014), "Board demographic diversity, firm performance and strategic change A test of moderation", Management Research Review, Vol. 37 No. 12, pp. 1110-1136. 
Urde, M. and Koch, C. (2014), "Market and brand-orientated schools of positioning”, Journal of Product and Brand Management, Vol. 23 No. 7, pp. 478-490.

Varela, J.A., Bande, B., Del Rio, M. and Jaramillo, F. (2019), "Servant leadership, proactive work Behavior, and performance overall rating: Testing a multilevel model of moderated mediation", Journal of Business-to-Business Marketing, Vol. 26 No. 2, pp. 177-195.

Vieira, V.A., Faia, V da S., Boles, J., Marioti, B.R. and Pereira, R.C. (2019), “The role of self-regulation mode on acquisition-retention ambidexterity", Journal of Business and Industrial Marketing, Vol. 34 No. 8, pp. 1813-1826.

Wagner, S.M. and Eggert, A. (2016), “Co-management of purchasing and marketing: Why, when and how?" Industrial Marketing Management, Vol. 52, pp. 27-36.

Weiland, P. E. (2007). The influence of regulatory mode on the use of limited self-regulatory resources and the experience of self-regulation. Doctoral dissertation. Retrieved from https://etd.ohiolink.edu/!etd.send_file?accession $1 / 4$ toledo1197423473\&disposition $1 / 4$ inli ne.

Wytykowska, A. and Gabińska, A. (2015), “The effect of emotions, promotion vs. prevention focus, and feedback on cognitive engagement”, Polish Psychological Bulletin, Vol. 46 No. 3, pp. 350-361.

Yang, Z., Zhang, H. and Xie, E. (2017), "Performance feedback and supplier selection: A perspective from the behavioral theory of the firm", Industrial Marketing Management, Vol. 63, pp. 105-115.

Zahay, D. and Griffin, A. (2010), “Marketing, strategy selection, marketing metrics, and firm performance", Journal of Business \& Industrial Marketing, Vol. 25 No. 2, pp. 84-93. 
Zhang, C., Ni, Y. and Feng, T. (2017), “The effect of regulatory mode on procrastination: Bistable parahippocampus connectivity with dorsal anterior cingulate and anterior prefrontal cortex", Behavioural Brain Research, Vol. 329, pp. 51-57.

Zhang, S., Liu, H. and Shi, R. (2016), "The dark side of "doing the right thing”: regulatory mode predicts the inaction inertia effect", Journal of Applied Social Psychology, Vol. 46 No. 11 , pp. $655-662$. 


\section{Tables}

Table 1: Study 1 - Reliability and validity indices

\begin{tabular}{|lccc|}
\hline & Cronbach's $\alpha$ & Composite Reliability & AVE \\
\hline Locomotion* & .929 & .913 & .683 \\
Interest & .878 & .942 & .778 \\
Mood start of survey & .957 & .948 & .786 \\
Mood end of survey & .965 & .973 & .878 \\
\hline
\end{tabular}

Note: * Removed scale item five

Table 2: Study 2 - Reliability and validity indices

\begin{tabular}{lccc|}
\hline & Cronbach's $\alpha$ & Composite Reliability & AVE \\
\hline Locomotion* & .925 & .942 & .765 \\
Assessment & .963 & .970 & .842 \\
Mood at start of & .942 & .952 & .798 \\
survey & .930 & .946 & .79 \\
Mood at end of survey & & & \\
Note: * Removed scale item one & &
\end{tabular}




\section{Figures}

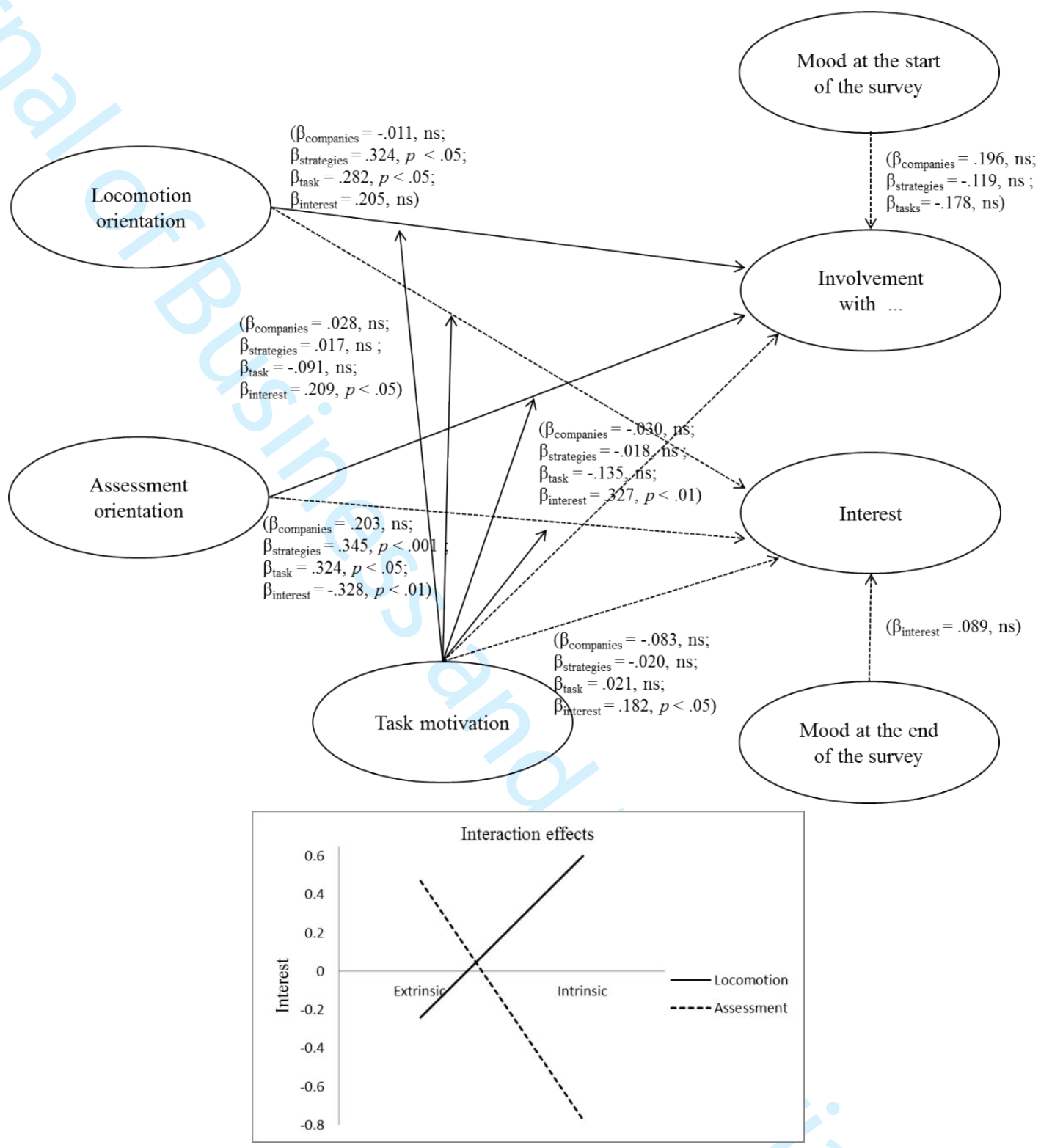

Note: 0 and 1 are correspondingly extrinsic and intrinsic rewards

Figure 1: Study 1 - Involvement with positioning strategy decision: Regulatory mode and activity engagement 


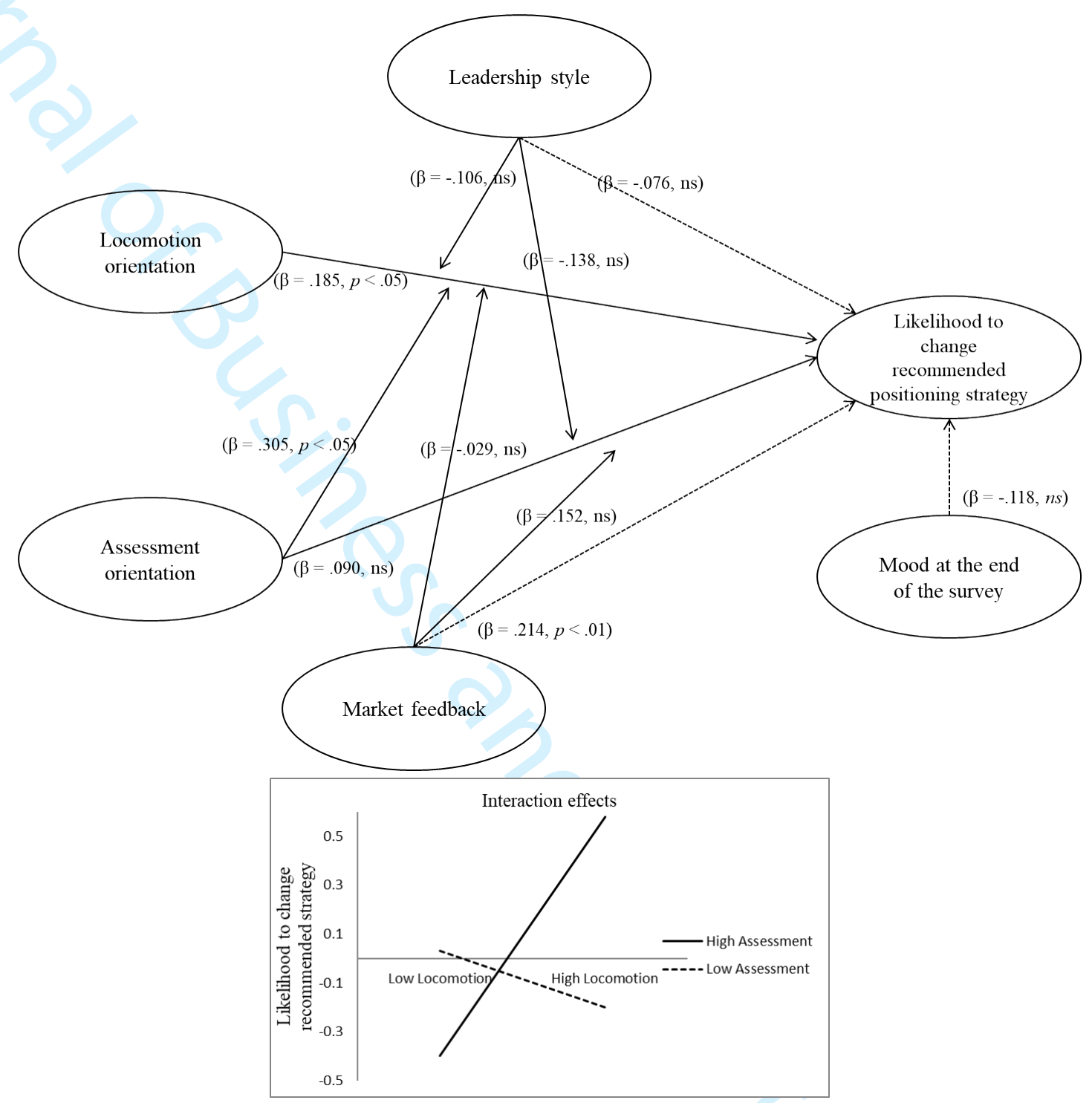

Note: 0 denotes positive $(+15 \%)$ market feedback and advisory leadership style while 1 denotes negative $(-15 \%)$ market feedback and forceful leadership style

Figure 2: Study 2 - Changing positioning strategy decision: Regulatory mode, leadership style and market feedback 